\title{
Translation, Context and the Public Sphere
}

\section{B. Hariharan}

\begin{abstract}
In Hariharan (2004:194) Hariharan discusses three levels of translation: (a) Translation as a personal enterprise (b) Translation as a cultural enterprise with a social mission and (c) Translation as cartographing social demography or translation as public enterprise. The "dimensions of translation in the public sphere" he says (ibid: 209) "possibly manifest best the change in a people and culture. Only a fuller study of the translations in the public sphere will enable an understanding of the cultural discourses that condition the transcreation of space." This paper proposes to address translation in the public sphere to understand how space gets transcreated. An attempt will also be made to explore the crucial question of the relationship between "the consequence of translation and the location of leisure" that he had briefly mentioned in his study cited earlier. The texts that form the basis for his argument which are considered here include the Connolly Canal that was once the artery of commerce in North Kerala, Kallai Over bridge that is only a memory now, and the City Centre, a multistoried building that towers above the older city centre, the Vadakkumnathan (Siva) temple in Trichur.
\end{abstract}

Translation and Translation Studies in the realm of Cultural Studies have become increasingly significant for the way in which

Translation Today Vol. 2 No. 2 Oct. 2005 @ CIIL 2005 
new languages shape the space of our living. While translation strongly implies a linguistic activity wherein printed texts are rendered in different cultures and languages, it is important to recognize that they were validated largely with the advent of the printing press and the movable type, what Benedict Anderson calls in his discussion of the origin of nationalism "print capitalism" (Anderson 1983:40) ${ }^{1}$. Translation as a scriptable, linguistic activity enables the shaping of specialized studies in the area requiring special linguistic skills that notify cultural texts and the translator's specific competence. An understanding, thus, of 'source' language and 'target' language where linguistic codes are transferred across linguistic and cultural boundaries has been the domain of Translation Studies. It is therefore possible to talk of inter-lingual, intra-lingual, and inter-semiotic translations and their problematic.

I propose to push the signification of 'translation' from the textuality of the printed word and work, from the question of the politics of who translates what and for whom, to a more flexible understanding of the term. What I propose to do here is not to look at the idea of translation and translation theory straight, but with a sidelong glance ${ }^{2}$. Since the signification of 'translation' and its cultural situatedness in a readership market describes the articulation of the economy of spatial production, it is important to describe the creation of cultural spaces and what they imply for translation.

In this context, it is appropriate to acknowledge that before the advent of print culture and the market economy, there were cultural translations. For instance, in his book Imagined Nations: Reflections on Media in Canadian Fiction, David Williams refers to King Alfred's ninth-century translation of Pope Gregory's Cura Pastoralis, with its important vernacular "Preface" (Williams 2003:24). Williams observes how a Saxon king might address a wider audience of Angelcynn in Old English, prefacing his translation of the Latin text in a manner that 'relentlessly integrates land, language, and people' (ibid:24). To extend the argument 
further, translation 'integrates land, language, and people'. What the rise of vernacular over Latin implied for King Alfred was "a loss of that national reputation". Yet, notes Williams, "the very memory of such a national past evokes a shared sense of community" (ibid:25). The shared sense of community evolves not out of print literacy, but through a different actualization of cultural space.

And so, while there are other ways to actualize cultural space that need not be authorized by books, located within the ambit of print culture, it will be culturally significant to discuss ways in which larger texts that configure societies, social attitudes, nations, empires, or even experiences of leisure are subject to translation. The texts that get translated need not, therefore, be in purely linguistic terms a rendering of source language to target language. Rather than address the linguistic, semantic, or culturally specific problems translations and translators face, it is proposed to address the way in which translation crosses linguistic boundaries and recasts, even re-inscribes new spaces that are of cultural significance. This is perhaps what Mary Ann Caws means when she talks of "inscribing in another language, your own...you are inscribing in your own language what someone else has said and inscribed in another language." (McCance 2001: 13)

In. Hariharan (2004) I argued that city-space could be seen as a cultural text subject to translation. It is to be noted here that Walter Benjamin worked on the Parisian Arcades from 1927 for thirteen years ${ }^{3}$. For him, the city, the architecture manifest in the Arcades, the flâneur, or the Ecole Polytechnique was all texts that articulate the dialectics of cultural space. Benjamin's incomplete project discusses a wide range of cultural texts in nineteenth century France within the larger text of the city and its arcades. Here's what Benjamin sets out to do with the Parisian Arcades:

"Here, the Paris arcades are examined as though they were properties in the hand of a collector. (At bottom, we may say, the collector lives a piece of dream life. For in the dream, too, the 
rhythm of perception and experience is altered in such a way that everything - even the seemingly most neutral - comes to strike us; everything concerns us. In order to understand the arcades from the ground up, we sink them into the deepest stratum of the dream; we speak of them as though they had struck us)" Benjamin (1999:205 206).

Benjamin's examination of the Parisian arcades locates the impact of iron and glass as construction material in the $19^{\text {th }}$ century. He argues that the impact of these building materials on construction and city-spaces is repeated with "the human material on the inside of the arcades....Pimps is the iron uprights of this street, and its glass breakables are the whores" (ibid: 874). The dialectics that he found in the arcades spoke for Benjamin, "not of decline but transformation. All at once, they were the hollow mold from which the image of 'modernity' was cast" [ibid: 874). Consider again what Benjamin says in one of his methodological reflections on "the evocation of the different districts of a great city. It is not their picturesque aspect that concerns the author, nor anything exterior. It is, rather, the unique character conferred on each of these quartiers by the social strata informing them and the occupations of the residents" (ibid:913). The transformation of the public sphere is truly a version of the process of translation of the cityscape. It is obvious that, to use Benjamin's phrase, "human material" is implicated in the transcreation of space.

What the translation of city-space underlines is the dialectics between 'human material' and the sites of processes those text new cultural discourses of space. The "dimension of translation in the public sphere" communicates the conditions that enable a realignment of the distribution of cultural spaces. Translation in the public sphere can be seen, to put it in Hariharan's words, to "possibly [manifest] best the change in a people and culture. Only a fuller study of the translations in the public sphere will enable an 
understanding of the cultural discourses that condition the transcreation of space."

With this intent, I would like to look at three distinct landmarks, of which two have an ancestry dating back to colonial times and one to very recent times. The Connolly Canal in Calicut district $^{4}$, and the Kallai and Feroke Road-bridge in Calicut date back to 1840 s and 1883 . The City Centre in the heart of Trichur city is an addition in the latter half of the last decade of the $20^{\text {th }}$ century.

Connolly Canal: To expand the facilities of water transport was drawn a very ambitious plan to link some rivers in North Malabar, which included Kotta river, Akala river, Elathur river, Kozhikode Kallai river, and Beypore river. As part of this project, in 1843 was constructed the 1.6 kilometer-long Payyoli watercourse linking the rivers, the Kotta and the Akala. This facilitated water transport between Badagara and Elathur. Later, in 1848, with the orders of the then collector of Malabar, Mr. Connolly, Elathur River, Kallai River and Beypore River were linked and the Connolly Canal watercourse was built.

As a result, it was possible to transport conveniently coconut, coconut husk, coir, black pepper, ginger, cardamom, coffee and tea from Badagara to Kozhikode and one could return to Badagara with tiles, bricks, rice and other commodities. This trade route was almost the lifeline of business, for there was hardly any other mode of transport connecting these places. Gradually, as road transport increased, this mode of transport had fewer users and by 1950 - '55 it stopped.

Today, there are no boats plying on this route. Instead, all the sewage of Calicut city gets emptied here and has become the breeding ground for mosquitoes. But, as recently as 1999, the tourist potential of the canal was recognized and as part of the actualization of new projects, serious renovation work was done here. This 
included constructing walls on either side. Removing silt and increasing the depth of the canal is continuing. The Calicut Corporation has prepared a big project called "Dream City" that covers about 247 acres of land that includes the marshy areas near Arayidathupalam, and land reclaimed from the candel overgrowths. It may be emphasized here that the candel growth is sanctuary to many migratory birds that breed only here because their breeding habits are environment-specific. The sports complex is also coming up with a project here. The Kerala tourism minister has gone on record saying that they are planning a one and half crore rupees project here. These projects might be realized, but, at present, Connolly Canal is an eyesore. The cosmetic beautification and fibreglass boats going in circles in the canal in wish-fulfillment augment this.

Alongside the canal, there is a mini bypass from Kalluthan wharf in the south to Karaparambu in the north. Because of this road, people frequent this place, there are programmes planned by different organizations, the corporation has exhibitions, annual celebrations, and other major events are held in the big ground here. People come here in the evening, and enjoy their time; dreaming under the shade of the trees their dream city.

A conceptual understanding of the impact the creation of such a communication network in the $19^{\text {th }}$ century had on the growth of trade, other modes of communication, and economy reveals primarily the functional transcreation of space that caters to a sustainable marketing route. This space unambiguously charts here a new language of communication. But it should also be noted that with laying new roads and infrastructure development, spaces that sustained economies till then became dead languages. Newer languages and their spaces become possible with different modes of communication. And yet, the dead language, the dead cultural text is further translated with its inherent potential to define newer cultural spaces. This is illustrated well in the translation of the dead 
communication network into a space that has tremendous tourist potential. It is also interesting to note that the Calicut Development Authority had taken up dredging work to increase the depth of the canal but it had to be abandoned, as there were other pressures. The idea was to link Badagara to Ponnani in Malappuram district, make travel cheaper and create new contexts for translating communication spaces.

But then, to return to the present situation, it must be observed that this translation in the context of the dynamics of larger movements of people across spaces makes over unambiguous languages into unresolved matrices that are caught in the marketability of the translation network itself. So the unfinished project viz. 'Dream City', the ongoing dream of expressing leisure in dreams and fiberglass boats. The new translation project exploring the tourist potential of the canal, then, re-makes even the name of the colonial district collector and the then interlinking of rivers the always already postmodern enterprise that prepares for the modernization project.

Kallai and Feroke Road-bridge: A discussion of railway and road-bridges will have to acknowledge the history of architecture and its relation to the appearance of iron in building technology. It might yet be useful to cite Benjamin to understand this advance in technology. As part of his dialectical reading of the French arcades, he studies iron construction that is in contrast "both with Greek construction in stone (raftered ceiling) and with medieval construction in stone (vaulted ceiling)" (ibid: 150); the study in turn engages with the history of construction work in at least two cities in Europe, Berlin and Paris.

For Benjamin, iron, the "artificial building material" (ibid: 4) was crucial for not just the arcades but also for the subsequent transcreation of the engineer and architect. Benjamin also underscores how there was significant development in the use of 
iron in relation to the locomotive, so much so that they were "compatible only with iron tracks" (ibid: 4). It is not merely a historical curiosity to observe that "[t]he rail becomes the first prefabricated iron component, the precursor of the girder. Iron is avoided in house-construction but used in arcades, exhibition halls, and train stations - buildings that serve transitory purposes." (ibid: $4,16)$ In other words, iron is "immediately allied with functional moments in the life of the economy" (ibid: 154).

Iron, which was functional in the life of the economy, at least when it was introduced in the construction of public spaces for transit purposes, in a dialectic contingent on history is translated into a landmark when the Kallai bridge or say, the bridge across Hooghly ${ }^{6}$ is considered today. It may be mentioned here that the Kallai and Feroke Road bridges were constructed and were commissioned in 1883 and the Hooghly bridge in 1897. The railway bridges across the Kallai and Feroke rivers were commissioned in 1888. These bridges, across the two rivers, were constructed when Lord Charles Napier was the Governor of Madras Presidency. The railway bridge across the two rivers was crucial for the Madras Railway trunk route along the west coast as they are today for the southern and Konkan railways.

Landmarks are defining factors for public space. They are the text of the public sphere. From the earlier 'functional moments in the life of economy', the bridge is translated to speak other 'functional moments' as it is landscaped as much more than a colonial structure. If the Kallai River figured in a classic Malayalam song of the seventies, in the late eighties the Kallai road bridge figured prominently in a popular Malayalam film titled Hey Auto. There is a wide-angle shot of the bridge with auto rickshaws blocking the car of the villain from either side where we witness intense drama as passions run high.

The road bridges across Kallai and Feroke rivers were probably the last remnants of British legacy in Calicut; it is not with 
nostalgia that the structure was seen to constitute the landscape. The two bridges were reminders of the demographic and sociological dimension of physical labour as well as an expression of the medium of communication translating as communal space. It might be useful to bear in mind that the material used in the construction was transformed into the medium of communication and had been an important link in networking and altering the social and demographic nature of the Malabar region.

Very recently, the Kallai road bridge was dismantled. This was part of the doubling of the railway line in the ShoranurMangalore sector. In the place of the iron structure that watched the sunset for more than a century, now is a concrete bridge constructed by the railways. A firm from Tiruchirapalli AMK \& Co, left with the iron structure that made up Kallai Bridge. It may be mentioned here that the tenders were opened in Tiruchirapalli for fear that there might be proactive demonstrations against the idea of demolition. The translation of the bridge as communal space was best seen when people protested on the site $^{7}$ when plans were drawn for the demolition work. Perhaps what must also be noted here is the translation of the old functional economics of iron into another language that speaks economics but on a much larger scale in terms of time saved to go to the northern part of the country, mass transport $^{8}$, and faster movement of freight. At another level, iron continues to be used as building material to reinforce concrete. And so, something in the 'source' text finds place in the 'target' text. It is possible to suggest that translation into communal space is the feeling, and experience of space that has shared cultural value.

The City Centre: I would like to cite here some short excerpts from Benjamin related to the arcades, capitalism, and the idea of phantasmagoria to read transcreations of public spaces that are expressions of commodification. Benjamin has used the word "phantasmagoria" 9 (ibid: 7) extensively to discuss the commodity character of nineteenth century culture. In the section titled 
'Convolutes' which is a major part of his work on the arcades, Benjamin sees "The arcades as temples of commodity capital" (ibid: 37). In the catalogue of materials for the Expose of 1935, we read, "The experience of our generation: that capitalism will not die a natural death" (ibid: 912). In "Paris, the Capital of the Nineteenth Century," he says, "The arcades are a center of commerce in luxury items. In fitting them out, art enters the service of the merchant" (ibid: 3). He further seeks to address the question, "Arcades as origin of department stores?" (ibid: 37).

Almost in answer to the question, in "The Ring of Saturn or Some Remarks on Iron Construction," Benjamin writes of the appearance of gas with cast iron in "those elegant establishments," the arcades. Here "The leading fancy-goods stores, the chic restaurants, the best confectioners, and so on found it necessary to secure a place in these galleries in order to preserve their reputations. Out of these galleries emerged, a little later on, the great department stores, of which the pioneering model, Au Bon Marche was designed by the builder of the Eiffel Tower" (ibid: 886). It is compelling to see the appearance of shopping malls in North America, our own supermarkets (the specialist and non-specialist varieties), and departmental stores as metamorphoses of the arcades for they are the temples of commodification.

The City Centre ${ }^{10}$ in Trichur is a temple that is an expression of phantasmagoria. This temple with a glass front faces the northwest corner of the Sree Vadakkumnathan Temple around which the city developed. It has ample car parking space in the basement, escalators and lift exposed to public gaze like a big capsule of glass encasing people as they go up and down. There is a fountain outside to complete the picture. Enquiries made around the place at random reveals that people are not sure as to what structures existed before the City Centre. There is vagueness as to the existence of two or three houses. In all likelihood, there might have been an old 
Nalukettu ${ }^{11}$. Public memory about private spaces becomes short when such spaces get translated into public space.

The new public space made of concrete and glass, towering above the temple dome (the temple is yet another public space), is assuredly ambivalent space unlike the Siva temple. An ambiguous public space located at a counter-point with other public spaces in the vicinity alters the language of the cityscape. If what Benjamin says about the use of glass in the Parisian arcades is true ${ }^{12}$, then the ambivalence has got to do with the building material used here. In the section on "Mirrors", Benjamin says, "A look at the ambiguity of the arcades: their abundance of mirrors, which fabulously amplifies the spaces and makes orientation more difficult. For although this mirror world may have many aspects, indeed infinitely many, it remains ambiguous, double-edged. It blinks: it is always this oneand never nothing - out of which another immediately arises" Walter Benjamin (ibid: 542). The glass front of the phantasmagoria with its glass elevators and alluring escalators, "the oppressive magic worked by the alluring mirror-walls of the arcades...invites us into seductive bazaars" (ibid: 541).

Inside this phantasmagoric temple are the City Centre Supermarket and other shops occupying shop space in the six floors. There is a Gold Park, shops selling leather goods, clothes, apparel, crockery, bakery, and cafeteria and snacks shop. One attraction is the availability of electronic appliances and imported goods, especially with a China bazaar, which has hot sales throughout. Computer games and other digital savvy entertainment co-exist with provisions, stationery items, household items, vegetables and other consumer durables. The creation of such languages of the interior effects the translation of human material as the site of consumption. The crowd puller is the Food Court on the third floor where one pays two hundred rupees, buys a credit card, and gets 'unlimited' food. The card seduces the exchange value of the consumer in the fetish for the value of commodity; the cardholder consumed in the 
seduction of the capitalist slogan of 'value for money'. This is the "Primordial landscape of consumption" (ibid: 827). This primordial landscape, one might conclude, is metamorphosed into the space that accommodates commodity.

This landscape of consumption is the amplification of not just the immediate space, but the language of the cityscape itself. For, the orientation inside is always through ambivalences generated through spaces replicated across floors "in the bosom of nothingness" (ibid: 878). And yet, here is made possible a collective space where are realized the aspirations, dreams, experiences of the city dweller; where leisure is expressed and experienced in the materiality of being human. While for Benjamin, the "street reveals itself in the arcade," (ibid: 879), here it may be said that the collective is re-inscribed in the phantasmagoria of the commodification of space. In its phantasmagoria, the City Centre becomes the 'real' City Centre.

Arguably translated spaces are always fluid, where meaning is never given, is being constantly moulded as it also moulds other spaces. In this sense, cultural translations are spatial inscriptions. They signify texts that are cultural processes transforming spaces and languages and their relationship is nothing less than 'human material'. Translation needs to be read as expressing the materiality of culture in spatial terms, not necessarily confined to the printed word, or the book.

\section{Notes}

1. Though Anderson (1983) discusses print-capitalism in relation to the rise of national consciousness, and in that context refers to Martin Luther's translation of the Bible, it serves equally to illustrate our point. He says, "But when in 1517 Martin Luther nailed his theses to the chapel-door in Wittenberg, they were 
printed up in German translation, and 'within 15 days [had been] seen in every part of the country.' In the two decades 1520 1540 three times as many books were published in German as in the period $1500-1520$, an astonishing transformation to which Luther was absolutely central. His works represented no less than one third of all German-language books sold between 1518 and 1525. Between 1522 and 1546 a total of 430 editions (whole or partial) of his Biblical translations appeared. 'We have here for the first time a truly mass readership and a popular literature within everybody's reach.' (ibid: 43). Translation and translator are caught unaware in the market economy ushered in with production technology. With the dissemination of the word of God in the vernacular, a reading public was brokered into place translating the "citadel of Latin" (ibid) into the vernacular creation of God's word as commodity.

2. I am indebted to Mary Ann Caws for the idea of the 'sidelong glance'. See the interview given to Dawne McCance (2001) in Mosaic.

3. I wish to acknowledge that Prof. Narayana Chandran drew my attention to the relevance of Benjamin's work for my discussion of city-space as cultural text.

4. I thank Mr. V. Ravindran, Retired Executive Engineer, Calicut Development Authority, Calicut, and V. Rakesh, contractor, Calicut, for valuable information on Connolly Canal.

5. Benjamin cites A. Gordon's argument against iron rails in the 1830s in his A Treatise in Elementary Locomotion in which Gordon argued that, "the steam carriage (as it was called then) should run on lanes of granite. It was deemed impossible to produce enough iron for even the very small number of railway lines being planned at that time" (1999:156).

6. Ian J. Kerr says that, "By mid-1850 Dalhousie had selected the routes and sanctioned the start of the construction of a 121-mile line in Bengal, extending north-westwards from Howrah (across the Hooghly river from Calcutta) to the small town of Raniganj, centrally situated with respect to the coal-fields of Bundwar, and 
a 35 mile line from Bombay east to Kalyan at the foot of the Western ghats" $(26-27)$. See Building the Railways in the Raj $1850-1900$.

7. There was, for instance, a core group led by Prof. Wilson H. Mackaden who had retired from the Dept of English, from Malabar Christian College that had actively led a campaign to 'save' the bridge. They had approached the court and had obtained an order that prevented further damage to heritage structures.

8. Walter Benjamin writes: "The historical signature of the railroad may be found in the fact that it represents the first means of transport - and, until the big ocean liners, no doubt also the last - to form masses. The stage coach, the automobile, the airplane carry passengers in small groups only" (1999:602).

9. The importance Benjamin attaches to the word 'phantasmagoria' can be gauged from the way it is used repeatedly in his discussions of commodification of culture. Rolf Tiedemann in "Dialectics at a Standstill: Approaches to the Passagen-Werk" appended to Benjamin's text argues that 'phantasmagoria' "seems to be merely another term for what Marx called commodity fetishism" (ibid: 938). Tiedemann says, "The fate of nineteenth century culture lay precisely in its commodity character, which Benjamin thereupon represented in 'cultural values' as phantasmagoria. Phantasmagoria: a Blendwerk, a deceptive image designed to dazzle, is already the commodity itself, in which the exchange value or value-form hides the use value. Phantasmagoria is the whole capitalist production process, which constitutes itself as a natural force against the people who carry it out" (ibid: 938).

10. I am grateful to Dr S. Satheesh and Dr E. Sandhya for providing additional details about the City Tower and the Siva temple in Trichur.

11. The Nalukettu is the traditional style of architecture of Kerala. The main feature here is that the house will have a quadrangle in the centre. The other important feature is the open central 
courtyard. Today it has become a status symbol for the well off.

12. Benjamin (1999: 877) says: "Where doors and walls are made of mirrors, there is no telling outside from in, with all the equivocal illumination. Paris is a city of mirrors".

\section{REFERENCES}

Anderson, Benedict (1983) Imagined Communities: Reflections on the Origin and Spread of Nationalism. London: Verso

Benjamin, Walter (1999) The Arcades Project. Trans. Howard Eiland and Kevin McLaughlin. Cambridge, Massachusetts, \& London: The Belknap Press of Harvard University Press.

Hariharan, B. (2004) "Translation: A Cultural Slide Show." Translation Today 1.2.

Kerr, Ian J. (1997) Building the Railways in the Raj 1850 - 1900. Delhi: Oxford University Press.

McCance, Dawne (2001) “'We Haven't Left the Body': An Interview with Mary Ann Caws." Mosaic.

Tiedemann, Rolf (1999) "Dialectics at a Standstill: Approaches to the Passagen-Werk." in Walter Benjamin (1999) The Arcades Project.Trans.Howard Eiland and Kevin McLaughlin. Cambridge, Massachusetts, \& London: The Belknap Press of Harvard UP.

Williams, David (2003) Imagined Nations: Reflections on Media in Canadian Fiction. Montreal \& Kingston: McGill University Press. 
